Case Report

\title{
Cerebral amyloid angiopathy: A case report
}

\section{Saini B ${ }^{\mathbf{1}}$.}

${ }^{1}$ Dr. Bharti Saini, Max Superspecialty Hospital, Mohali, Punjab, India.

Corresponding Author: Dr. Bharti Saini, Max Superspecialty Hospital, Mohali, Punjab, India. E-mail: bhartisaini806.bs@gmail.com

\begin{abstract}
Cerebral amyloid angiopathy (CAA) is a cerebrovascular disorder caused by the accumulation of cerebral $\beta$ amyloid (A $\beta$ ) in the media and intima of leptomeningeal and cortical vessels of the brain. The resultant vascular fragility tends to manifest in normotensive elderly patientsas lobar intracerebral hemorrhage and is a common cerebral amyloid deposition disease.
\end{abstract}

Key-words: Amyloid angiopathy, Ptosis, Diabetes, Hypertension.

\section{Introduction}

CAA also known as congophilic angiopathy is an important cause of spontaneous cortical-subcortical Intracranial hemorrhage $(\mathrm{ICH})$ in the normotensive elderly. Most common presentation is development of focal neurological deficits and cognitive impairment secondary to acute ICH [1].

It is frequently an overlooked cause of intracerebral hemorrhage $(\mathrm{ICH})$ which accounts for $10-20 \%$ of all strokes [2,3].

In normotensive individuals CAA is considered as a cause of multiple, recurrent intra-cerebral hemorrhages. CAA affects both the

\section{Case History}

70 years old known diabetic and hypertensive patient came to our hospital with complains of restricted ocular movement with sluggishly reactive pupil and ptosis since past few days. Rest of the physical examination was normal.

Other investigations: Hematology: Complete blood count, renal function tests, liver function tests, serum calcium levels were within normal limits.

Urine routine and microscopy: Traces of albumin and1-2 RBCs.

Then, patient was referred to radiology department for magnetic resonance imaging (MRI) scan.

MRI shows periventricular leucomalacia on FLAIR images and multiple blooming foci (microhemorrhages) on susceptibility weighted images at gray white matter. Interface in both cerebral hemispheres with sparing of bilateral basal ganglia region (Figure 1,2).

Manuscript received: $30^{\text {th }}$ March 2018

Reviewed: $7^{\text {th }}$ April 2018

Author Corrected: $14^{\text {th }}$ April 2018

Accepted for Publication: 17 $7^{\text {th }}$ April 2018 cortical and leptomeningeal vessels, but pure subarachnoid or subdural hemorrhage is rare [4]. CAA may have different manifestation in form of CAA related inflammation and Cerebral amyloidoma.

CAA can be of sporadic and familial forms, familial forms are often part of multi-system involvement. Modified Boston Criteria is used for its diagnosis.

On red stain, CAA involved vessels have a characteristic apple-green birefringence under polarised light. CAA is immunoreactive for matrix metalloproteinase which further aids in diagnosis. 

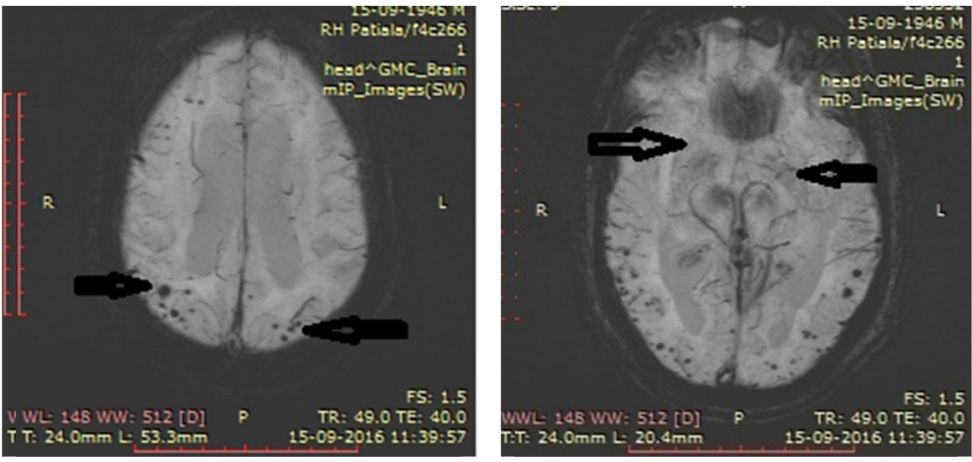

\section{Case Report}

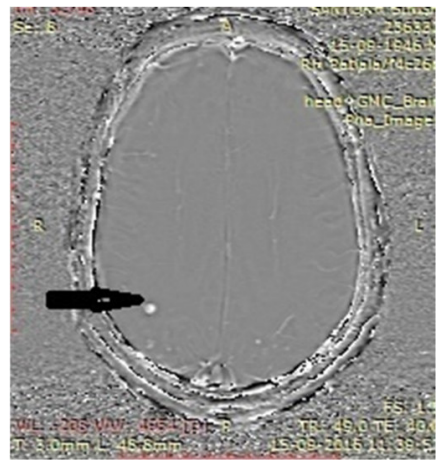

Figure 1: Susceptibility weighted images (MIP and phase) shows multiple blooming /hyperintense foci at gray white matter interface with sparing of bilateral basal ganglia region (Arrows)
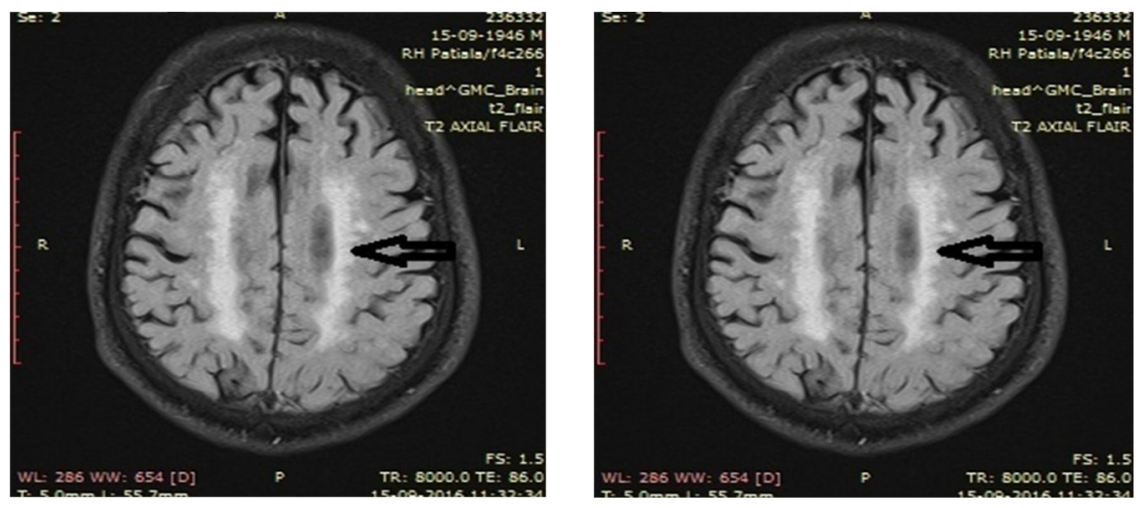

Figure 2: FLAIR MRI images show the periventricular leucomalacia (Arrows)

\section{Discussion}

CAA is the $3^{\text {rd }}$ most common cause of ICH after hypertension in the elderly patients [5]. CAA accounts for $10.9 \% \mathrm{ICH}$ in a study conducted by Itoh and Yamada [6]. At gray -white matter junction, the risk of re bleeding seemed to be high which is typically considered as a site of hemorrhagein CAA [7,8]. Three common locations of amyloid deposition in cerebral tissue are 1) Brain parenchyma as an extension from vessel wall; 2) neurons as neurofibrillary tangles; 3) walls of leptomeningeal and cortical vessels. Cortical lobes are most commonly affected in CAA.

Basal ganglia, thalami and brainstem are usually spared. CAA related ICH most commonly located in the parietal lobes [8]. Basal ganglia and cerebellar hemispheres are usually involved in hypertensive microangiopathy and are spared in CAA [8] similar to present study. Lobar type hemorrhageis most common seen in ICH which most commonly rupture into the subarachnoid space resulting in subarachnoid hemorrhage (SAH). CAA related ICH can also disrupt the white matter and rupture through the ependyma into the ventricular system resulting in intraventricular extension [8]. So these features help to distinguish between CAA and hypertensive microangiopathy which also had clinical importance for the physician.

\section{Conclusion}

CAA related ICH typically affects the gray white interface and its lobar distribution with sparing of basal ganglia and cerebellar hemispheres helps it to distinguish from hypertensive related microangiopathy.

Funding: Nil, Conflict of interest: None

Permission of IRB: Yes

\section{References}

1. Christine P. Chao, Amy L. Kotsenas, Daniel F. Broderick : Cerebral Amyloid Angiopathy: CT and MR Imaging Findings. Radio Graphics. 2006;26 (5):15171531.

2. Feigin VL, Lawes CM, Bennett DA, Anderson CS. Stroke epidemiology: a review of population-based studies of incidence, prevalence, and case-fatality in the late $20^{\text {th }}$ century. Lancet Neurol. 2003; Jan; 2 (1): $43-53$. 


\section{Case Report}

3. Ariesen MJ, Claus SP, Rinkel GJ, Algra A. Risk factors for intracerebral hemorrhage in the general population: a systematic review. Stroke. 2003; 34 (8): 2060-5.

4. Vinters HV: Cerebral amyloid angiopathy: A critical review. Stroke 1987;Mar-Apr;18(2):311-24.

5. O'Donnell HC, Rosand J, Knudsen KA, Furie KL, Segal AZ, Chiu RI, Ikeda D, Greenberg SM. Apolipoprotein E genotype and the risk of recurrent lobar intracerebral hemorrhage. N Engl J Med. 2000 Jan $27 ; 342$ (4): 240-5.
6. Itoh Y, Yamada M. Cerebral amyloid angiopathy in the elderly: the clinicopathological features, pathogenesis, and risk factors. J Med Dent Sci. 1997 Mar; 44(1):11-9.

7. Passero S, Burgalassi L, D'Andrea P, Battistini $\mathrm{N}$. Recurrence of bleeding in patients with primary intracerebral hemorrhage.Stroke.1995Jul;26(7):1189-92

8. Zhan RY, Tong Y, Shen JF, Lang E,C Preul C, Hempelmann RG. Study of clinical features of amyloid angiopathy hemorrhage and hypertensive intracerebral hemorrhage. J Zhejiang Univ Sci. 2004 Oct; 5 (10): 1262-69.

\section{How to cite this article?}

Saini B. Cerebral amyloid angiopathy: A case report. Int J Med Res Rev 2018;6(04):210-212. doi:10.17511/ijmrr. 2018.i04.03. 